\title{
The Synaptic Vesicle Proteins Synapsin I and Synaptophysin (Protein P38) Are Concentrated Both in Efferent and Afferent Nerve Endings of the Skeletal Muscle
}

\author{
P. De Camilli, ${ }^{1}$ M. Vitadello, ${ }^{2,3}$ M. P. Canevini, ${ }^{1}$ R. Zanoni, ${ }^{3}$ R. Jahn, ${ }^{4}$ and A. Gorio ${ }^{3, a}$ \\ ${ }^{1}$ CNR Center of Cytopharmacology and Department of Medical Pharmacology, University of Milan, ${ }^{2}$ Istituto di Fisiologia \\ dei Centri Nervosi del CNR, Milan, and ${ }^{3}$ Fidia Research Laboratories, Abano Terme, Padua, Italy; and ${ }^{4}$ Max-Planck-Institut \\ für Psychiatrie, Abteilung Neurochemie, 8033 Martinsried bei München, FRG
}

\begin{abstract}
Synapsin I and synaptophysin (protein p38) are 2 major protein components of the membranes of small synaptic vesicles of virtually all presynaptic nerve endings. Synapsin I, a phosphoprotein regulated by both $\mathrm{Ca}^{2+}$ and CAMP, is a peripheral protein of the cytoplasmic surface of the vesicle membrane. It is thought to anchor the vesicle surface to the cytoskeleton of the terminal and to play a regulatory role in neurotransmitter release. Synaptophysin is an Intrinsic transmembrane glycoprotein.

We report here that both proteins are present and concentrated also in afferent nerve endings, which provide the sensory innervation of the skeletal muscle and of the tendon. The distribution of both antigens in sensory nerve endings is consistent with their localization on the microvesicles that have been described in such endings. Thus, our results suggest the existence of important biochemical, and possibly functional, similarities between small synaptic vesicles of presynaptic nerve endings and microvesicles of sensory endings. Such findings provide new clues to the understanding of the physiology of sensory endings.
\end{abstract}

Synapsin I and synaptophysin (to which we have previously referred as protein p38), are 2 major protein components of small synaptic vesicle membranes (Navone et al., 1984, 1986; Jahn et al., 1985; Wiedenmann and Franke, 1985; De Camilli and Greengard, 1986). Each protein represents approximately $6 \%$ of the total protein in a highly purified fraction of small synaptic vesicles (Huttner et al., 1983; Jahn et al., 1985). Synapsin I is a nerve cell-specific protein. It is a peripheral protein of the cytoplasmic surface of the vesicle and is thought to act as a link protein between the vesicle and the cytoskeletal matrix of the terminal (Ueda and Greengard, 1977; De Camilli et al., 1983a, b; Huttner et al., 1983; Navone et al., 1984). It is a phosphoprotein that can be phosphorylated at multiple sites by cAMP-dependent protein kinase and by types I and II $\mathrm{Ca}^{2+} /$ calmodulin-dependent protein kinases (Huttner et al., 1981;

\footnotetext{
Received Apr. 1, 1987; revised Aug. 18, 1987; accepted Sept. 26, 1987.

We thank P. Tinelli for technical assistance. This work was supported in part by grants from MDA, the Italian CNR (84.02274.56 and 85.00528.56), and the Italian Department of Education (to P.D.C.).

Correspondence should be addressed to P. De Camilli at the above address.

aPresent address: Istituto di Farmacologia e Farmacognosia, Universita' di Milano, Via Balzaretti 9, 20129 Milano, Italy.

Copyright (C) 1988 Society for Neuroscience $0270-6474 / 88 / 051625-07 \$ 02.00 / 0$
}

Kennedy and Greengard, 1981). Phosphorylation of synapsin I is thought to play a regulatory role on the exo-endocytotic cycle of synaptic vesicles (see De Camilli and Greengard, 1986, for a review). Synaptophysin is an intrinsic transmembrane glycoprotein (Jahn et al., 1985; Wiedenmann and Franke, 1985). It is present not only in neurons but also in non-neuronal neuroendocrine cells, where it is localized on a population of microvesicles distinct from secretory granules (Navone et al., 1986). The function of synaptophysin is unknown.

Light-and electron-microscopy immunocytochemical studies have shown that synapsin I and synaptophysin are present on small synaptic vesicles at virtually all synapses (De Camilli et al., 1983a, b; Navone et al., 1984, 1986). Both proteins are regarded as markers for presynaptic nerve endings, since the presence of small synaptic vesicles is a key feature of presynaptic compartments. Small vesicles, however, are also present in at lcast some sensory nerve endings. They are morphologically similar to presynaptic small synaptic vesicles, but they are more scattered in such endings than in presynaptic terminals (Landon, 1972; Barker, 1974). The physiological function of microvesicles in sensory endings is not known.

We report here a study on the innervation of the skeletal muscle in which we show that both synapsin I and synaptophysin are concentrated not only in efferent motor endings, as was reported previously, but are also present and concentrated in sensory endings of both the muscle proper and the tendon. Preliminary accounts of this work have been presented previously (De Camilli et al., 1985).

\section{Materials and Methods}

Antibodies and cytochemical reagents. Rabbit antibodies directed against synapsin I and synaptophysin purified from bovine brains, were prepared, and characterized as previously described (De Camilli et al., 1983a; Jahn et al., 1985). Monoclonal IgGs directed against the rat $150,000 \mathrm{Da}$ neurofilament subunit (monoclonal IC8) and against synaptophysin were prepared and characterized as described (Jahn et al., 1985; Vitadello et al., 1986). Rhodamine-conjugated goat anti-rabbit IgGs and fluorescein-conjugated rabbit anti-mouse IgGs were from Cooper Biochemical (Malvern, PA) or from DAKO (Danmark). Alphabungarotoxin (Sigma, St. Louis, MO) and IC8 IgGs (prepared by ammonium sulfate precipitation from ascitic fluids) were coupled to fluorescein isothiocyanate (Serva Feinbiochemica, Heidelberg, W. Germany) using the dialysis bag procedure (Clark and Sheppard, 1963). Briefly, a dialysis bag containing $1 \mathrm{mg}$ protein in $1 \mathrm{ml}$ of $0.05 \mathrm{M}$ sodium carbonate buffer, pH 9.5 , was kept for $18 \mathrm{hr}$ at $4{ }^{\circ} \mathrm{C}$ in a test tube containing $10 \mathrm{ml}$ of the same buffer, to which $20 \mu \mathrm{g}$ of fluorescein isothiocyanate had been added. At the end of such incubation, unbound 


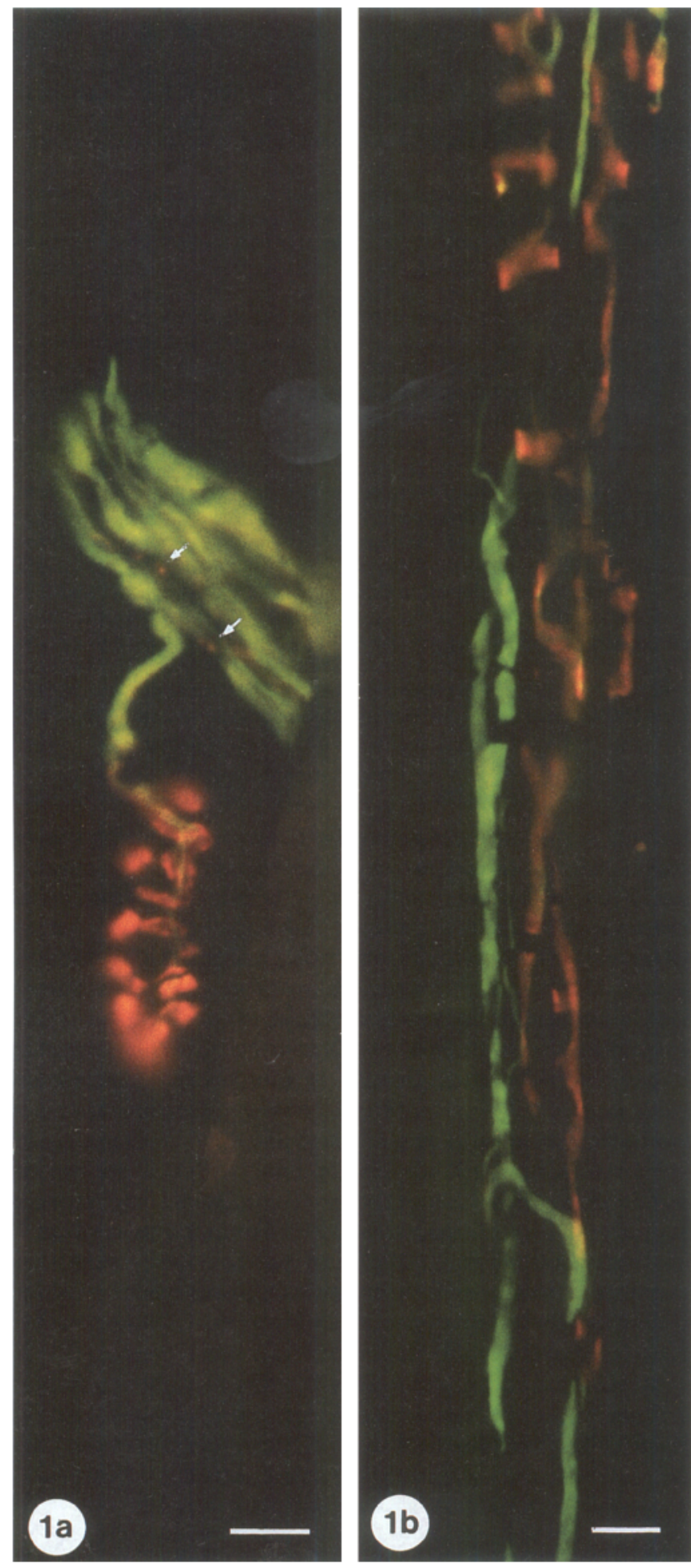

Figure 1. Double-staining of frozen sections of rat skeletal muscle for synapsin I by immunorhodamine ( $r e d$ ) and for neurofilaments by immunofluorescein (green). $a$, A motor nerve terminal. $b$, A sensory nerve terminal of a muscle spindle. Neurofilament stain was used to demonstrate preterminal axons. Both motor and sensory endings contain high concentrations of synapsin I immunoreactivity. Since synapsin I is restricted to the terminal region, where neurofilaments are less abundant, synapsin I immunoreactivity and neurofilament immunoreactivity seem to have an almost complementary distribution. Small arrows in $a$ point at synapsin I-immunoreactive dots, which represent varicose sympathetic fibers coursing in the small nerve branch. Bars: $10 \mu \mathrm{m}(a)$; $20 \mu \mathrm{m}(b)$. fluorochrome was eliminated by dialysis against phosphate-buffered saline.

Tissue preparation and immunocytochemistry. Sprague-Dawley albino rats, 175-250 gm, were anesthetized and fixed by transcardial perfusion as described (De Camilli et al., 1983a). The fixative was $4 \%$ formaldehyde (freshly prepared from paraformaldehyde). At the end of the perfusion, skeletal muscles (extensores digitorum longi) were removed and immersed in the same fixative for an additional $3 \mathrm{hr}$. After a rinse in phosphate-buffered saline (several hours), muscles were infiltrated with $18 \%$ sucrose and subsequently frozen in freon chilled in dry ice. Longitudinal frozen sections, 12-20 $\mu$ m thick, were prepared in a Reichert-Jung cryostat.

Single immunostaining of sections for synapsin I or for synaptophysin was performed by an indirect immunorhodamine procedure as described (De Camilli et al., 1983a). At the end of this staining, some sections were further labeled for acetylcholine receptors or for neurofilaments by being overlaid $(30 \mathrm{~min})$ with either fluorescein-conjugated alpha-bungarotoxin $(10 \mu \mathrm{g} / \mathrm{ml}$ in phosphate-buffered saline) or with fluorescein-conjugated IC8 monoclonal antibodies $(10 \mu \mathrm{g} / \mathrm{ml})$. Double-staining for synapsin I and for synaptophysin was carried out by labeling sections first for synapsin I by immunorhodamine and then for synaptophysin by immunofluorescein. At the end of the staining, glass slides were mounted with $95 \%(\mathrm{vol} / \mathrm{vol})$ glycerol in $120 \mathrm{~mm}$ sodium phosphate buffer or Elvanol (Garzanti Chimica, Milan) (Thomason and Cowart, 1967) and observed with a Zeiss photomicroscope III equipped with epifluorescence and planapo objectives. Black and white pictures were taken with technical pan 2415 film, which was developed with undiluted D 19. Color pictures were taken with Ektachrome 100 or 200. Films and chemicals were from Kodak (Rochester, NY).

\section{Results}

The distribution of synapsin I in somatic efferent motor nerves of the skeletal muscle, demonstrated by immunofluorescence in frozen tissue sections, is shown in Figures $1 a$ and $2 a$. Doublelabeling of the same tissue sections for synapsin I and for neurofilaments (to reveal preterminal axons) clearly shows that synapsin I immunoreactivity is confined to the end region of the axon (Fig. 1a). The transition between the synapsin I-rich and the synapsin I-poor regions of the axon appears very sharp. In the fingerlike processes that constitute the nerve terminal, synapsin I is unevenly distributed. It is concentrated in the most peripheral portions of the cytoplasm, i.e., those regions that are directly apposed to the nicotinic receptor-enriched portions of the postsynaptic membrane. This is clearly shown by the precise topological correspondence between the presynaptic focal accumulation of synapsin I immunoreactivity and the postsynaptic focal accumulation of alpha-bungarotoxin binding sites (Fig. 2, $a, b$ ). Alpha-bungarotoxin is known to bind with high affinity to the muscular nicotine receptor (Lee et al., 1972).

Synapsin I immunoreactivity was also found at high concentration in sensory nerve endings. At muscle spindles a variety of synapsin I-immunoreactive fibers could be identified. Some of these had a spiral shape (Figs. 1 $b, 3$ ). Others formed less regular arrays around muscle cells (bottom of Fig. 3, and not shown). The shape of these various types of fibers resembled the shape of the sensory endings previously described at muscle spindles (see Barker, 1974, for a review). At the polar regions of the spindle, some synapsin I-positive nerve endings with a morphology reminiscent of that of motor nerve endings were also visible. These endings, which were in register with alphabungarotoxin binding sites (not shown), probably represented motor endings of beta and gamma motor fibers.

In the tendons, highly branched synapsin I-immunoreactive fibers with the morphology described for sensory nerve endings of the Golgi tendon organs ("organo nervoso musculo tendineo"; Golgi, 1903) were visible (Fig. 4). At high magnification 

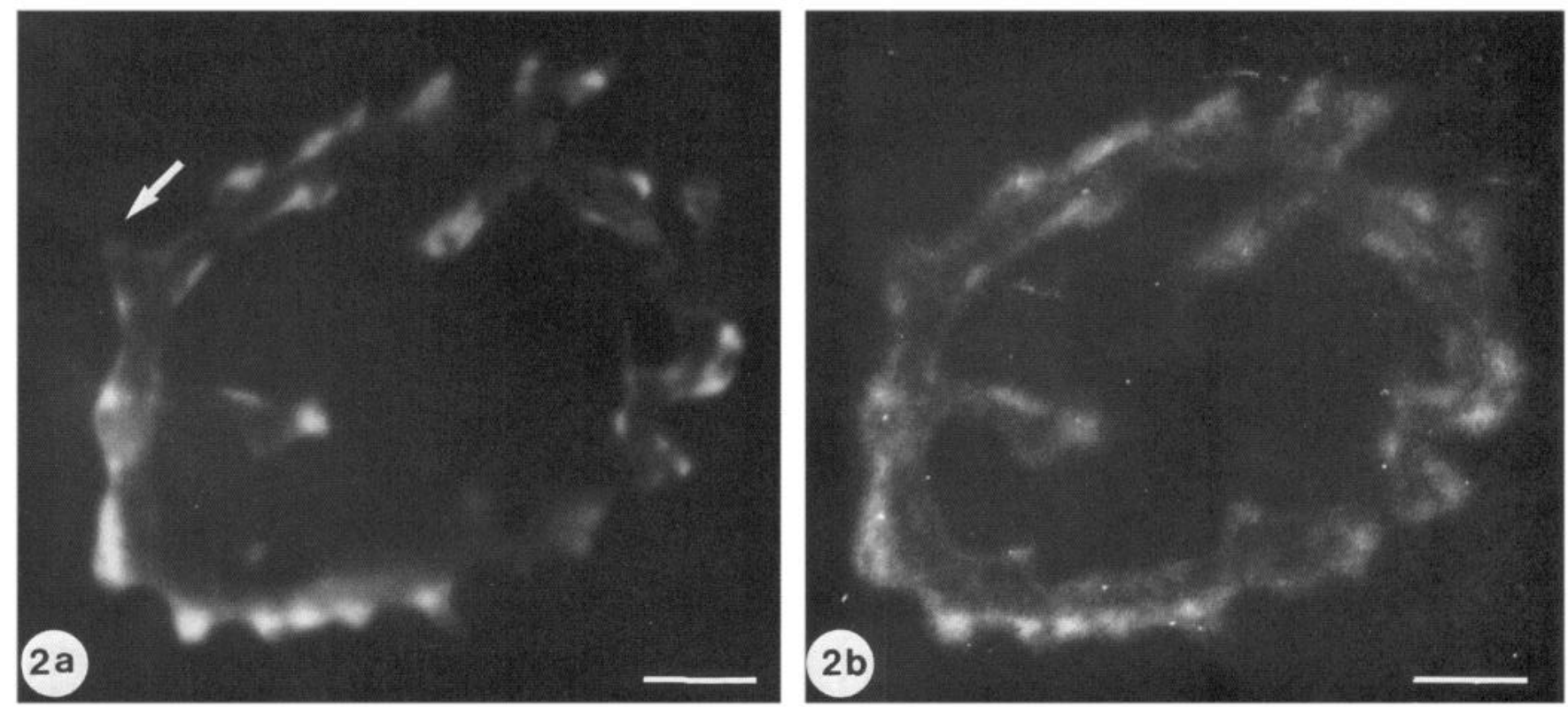

Figure 2. Double-staining of a frozen section of rat skeletal muscle for synapsin I by immunorhodamine (a) and for acetylcholine (nicotinic) receptors by fluorescein-conjugated alpha-bungarotoxin $(b)$. Note the accumulation of synapsin I immunoreactivity $(a)$ at focal sites in the cortical cytoplasm of the ending. These sites are in precise correspondence with alpha-bungarotoxin binding sites $(b)$. An arrow in $a$ points at the site of transition between the preterminal axon and the terminal. Bars, $5 \mu \mathrm{m}$.

these axon endings appeared to have the shape of flattened processes wrapped around small tendon fascicles.

As was seen in the case of motor nerves, in sensory nerves of both the muscle and the tendon, synapsin I was concentrated in the end region, with a sharp transition occurring between synapsin I-poor and synapsin I-rich regions. This was clearly seen in sections double-stained for synapsin I and for neurofilament proteins (Figs. 1 $b, 4$ ). However, high-power observation of sections stained for synapsin I revealed that this protein had a more homogeneous, diffuse distribution in sensory endings than in motor nerve endings (Fig. 5). Conversely, neurofilaments, which in motor nerve endings were organized in tight bundles in the central core of the endings, were dispersed in sensory endings and often almost undetectable by immunostaining (not shown).

Like synapsin I, synaptophysin was also found not only in motor endings, but also in all types of sensory endings of the muscle and of the tendon. The presence of synaptophysin immunoreactivity in motor nerve endings and in sensory endings of the muscle spindle and of the Golgi tendon organ is shown in Figure 6. Double-labeling of the same tissue sections for synapsin I and for synaptophysin revealed that the distribution of immunoreactivity for the 2 proteins was identical in all terminals (Fig. 7, and not shown).

\section{Discussion}

In this paper we report that synapsin I and synaptophysin (previously referred to by us as p38), 2 major protein constituents of the membrane of small synaptic vesicles of efferent nerve endings (De Camilli et al, 1983; Huttner et al., 1983; Navone et al., 1984, 1986; Jahn et al., 1985; Wiedenmann and Franke, 1985), are also present and concentrated in afferent nerve endings of muscle spindles and tendons.

Synapsin I is an extrinsic protein of the vesicle membrane that is thought to be involved in anchoring vesicles to the cy- toskeleton of the terminal (see De Camilli and Greengard, 1986, for a review). It is a protein synthetized on free ribosomes (De Gennaro et al., 1983) and, although a large body of morphological and biochemical evidence suggests that the bulk of synapsin I is vesicle-associated (De Camilli and Greengard, 1986), a pool of nonvesicular synapsin $I$ is expected to exist in the cell. Thus, the presence of synapsin $I$ in afferent nerve endings would not necessarily imply that in such endings synapsin I is localized on vesicles. Synaptophysin, however, is an integral transmembrane protein (Jahn et al., 1985; Wiedenmann and Franke, 1985). Thus, the colocalization of synapsin I and of synaptophysin (at least at the level of resolution of light microscopy) in all types of sensory endings of the muscle and the tendon is consistent with the idea that in sensory endings too, synapsin I is primarily localized on an intracellular membrane system.

Microvesicles morphologically similar to small synaptic vesicles of presynaptic endings are known to be present and concentrated in sensory endings of the muscle (Landon, 1972; Barker, 1974). It is therefore likely that the presence of both synapsin I and synaptophysin in sensory endings is due to their localization on the membranes of such microvesicles. Furthermore, consistent with this idea, the 2 proteins have an identical, more diffuse, distribution in sensory endings than in motor endings. This distribution parallels the scattered distribution of microvesicles in sensory endings (Landon, 1972; Barker, 1974), in contrast to their dense packing at subplasmalemma sites in efferent endings.

These results imply that microvesicles of sensory endings share not only morphological but also important biochemical similarities with small synaptic vesicles of presynaptic endings. Given the virtually ubiquitous presence of synapsin I and synaptophysin at presynaptic terminals, it can be inferred that these proteins are also present at the presynaptic endings of the centrally directed axons of sensory neurons. Thus, our results are not surprising if one considers that the same pattern of proteins 


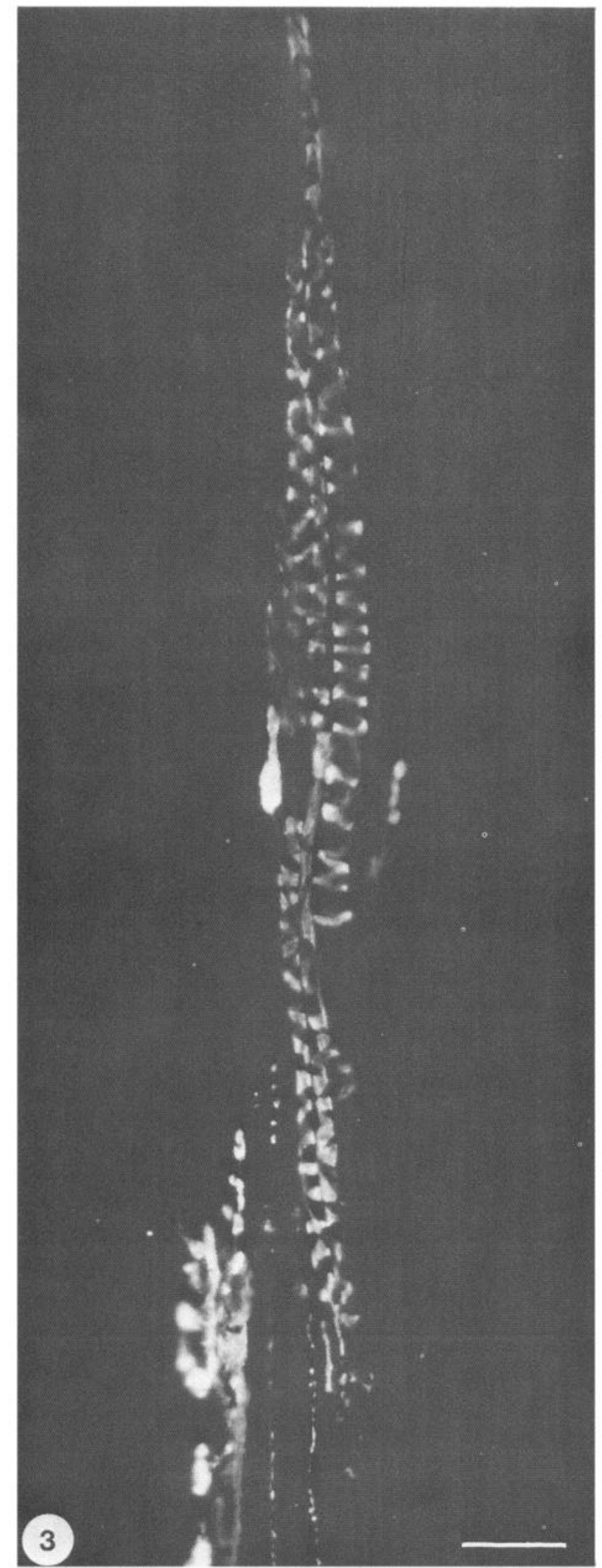

Figure 3. Presence of synapsin I in the sensory endings of a muscle spindle as demonstrated by immunofluorescence. The field shows primarily annulospiral endings, but other types of endings are also visible at the bottom. Bar, $40 \mu \mathrm{m}$.

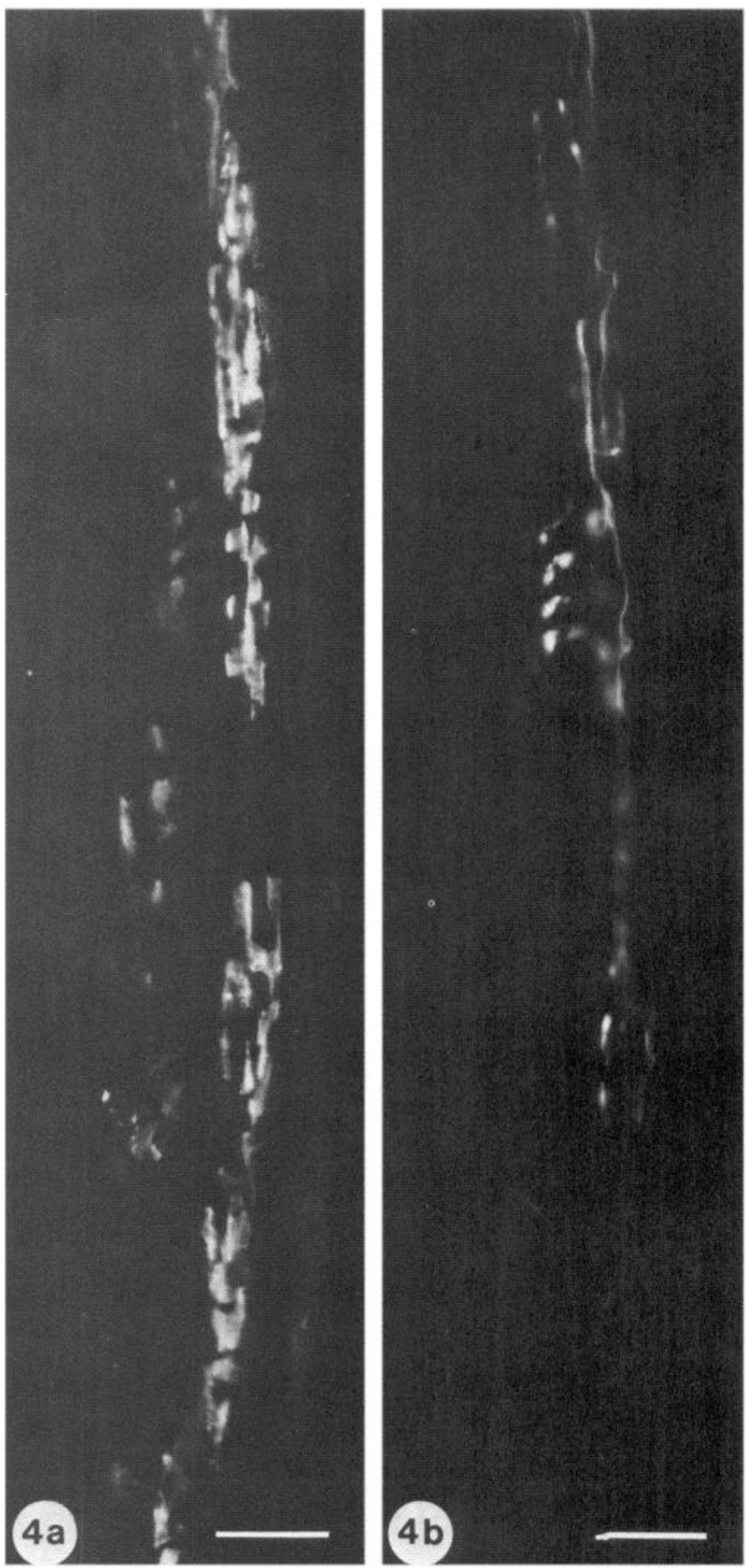

Figure 4. Presence of synapsin I in the sensory endings of a Golgi tendon organ. The 2 micrographs show the same organ double-stained by immunofluorescence for synapsin I $(a)$ and for neurofilaments $(b)$. As in the case of motor axons and of sensory axons that innervate muscle spindles, in axons that innervate Golgi tendon organs synapsin $\mathrm{I}$ is also restricted to the terminal region. Preterminal axon segments visualized by neurofilament stain $(b)$ are synapsin I-negative. Bars, 20 $\mu \mathrm{m}$.

is transported along the central and peripheral branches of sensory neurons (Watson et al., 1975; Mori et al., 1979; Stone and Wilson, 1979).

We do not know, at present, whether synapsin I and synaptophysin are concentrated in all afferent endings. Both these proteins, however, are also present at high concentrations in at 


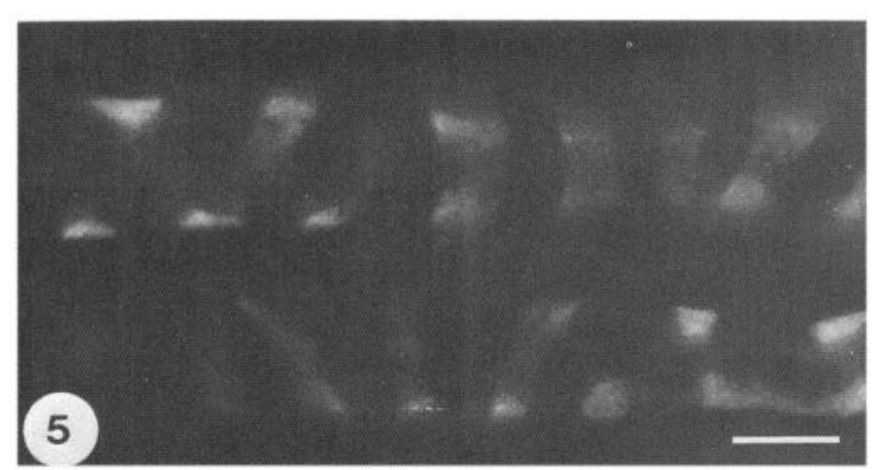

Figure 5. High-power view of a muscle spindle immunostained for synapsin I. Synapsin I immunoreactivity has a homogeneous, diffuse distribution. (Some apparent heterogeneity of the immunostain is due to an optical effect related to the geometry of the ending.) Bar, $20 \mu \mathrm{m}$.

least another type of sensory ending we have investigated, i.e., that of the vestibular neuroepithelium (Favre et al., 1986; and E. Scarfone, D. Dememes, R. Jahn, P. De Camilli, and A. Sans, unpublished observations). The subregions of these endings where synapsin I and synaptophysin are concentrated are densely populated by microvesicles (E. Scarfone, D. Dememes, R. Jahn, P. De Camilli, and A. Sans, unpublished observations).

The function of microvesicles in sensory endings is unknown. It is unlikely that the presence in peripheral endings of sensory neurons of microvesicles biochemically similar, if not identical, to presynaptic vesicles is simply the result of a lack of mechanisms to direct cellular traffic at the bifurcation of their single axon. The presence of microvesicles and of presynaptic vesicle antigens in sensory endings of the vestibular neuroepithelium as well (see above) seems to rule out this possibility. Neurons of the otic ganglion, i.e., the neurons that provide the afferent innervation of the vestibular neuroepithelium, are bipolar rather than pseudounipolar (Ramon y Cajal, 1911), and their afferent and efferent processes originate from different regions of the perikaryon.

Microvesicles of afferent endings are likely to play a role in the physiology of sensory nerves, and our results suggest that at least some of their properties might be related to those of vesicles of efferent endings. One possibility is that, similar to their counterparts in efferent endings, sensory microvesicles might be involved in the storage and secretion of classical neurotransmitter molecules, probably the same molecules secreted by the central processes of sensory neurons. The more scattered distribution of microvesicles in sensory nerve endings than in efferent nerve endings might be related to the different temporal and topological properties of secretion from sensory endings. It is interesting that black widow spider venom, thought to act only on nerve terminals (Hurlbut and Ceccarelli, 1974; Valtorta et al., 1984; Meldolesi et al., 1986), produces in afferent endings morphological changes similar to those that have been reported to occur in efferent endings. These include a disappearance of small vesicles and a swelling of the terminal (Queiroz and Duchen, 1982). In efferent endings, these changes have been shown to be due to a massive stimulation of exocytosis of small synaptic vesicles (Hurlbut and Ceccarelli, 1974). The similar changes observed in afferent endings might be due to a like stimulation of exocytosis of microvesicles, and thus reflect the existence of a similar secretory mechanism in both types of endings.

The existence in somatic sensory endings of the skeletal muscle of a secretory machinery might imply that these endings are
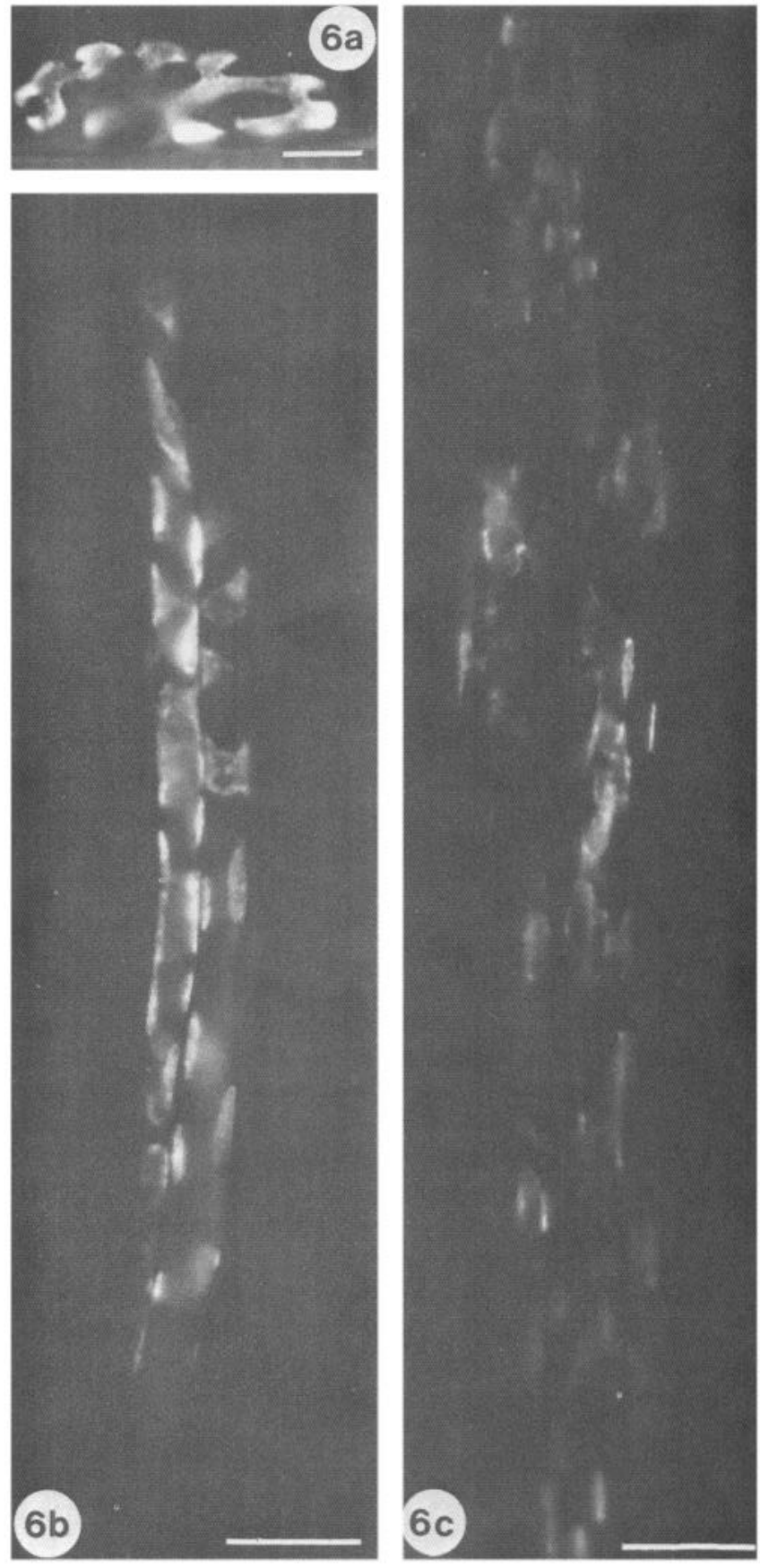

Figure 6. Immunofluorescence localization of synaptophysin immunoreactivity in nerve endings of the skeletal muscle. $a$, Motor nerve ending. $b$, Annulospiral ending of a muscle spindle. $c$, Nerve endings of a Golgi tendon organ. Bars: $20 \mu \mathrm{m}(a) ; 15 \mu \mathrm{m}(b, c)$.

able to modulate, via release of neurotransmitter molecules, some aspect of sensory transduction. It should be noted that large dense-core vesicles and peptide neurotransmitters have also been found in at least some types of sensory endings (for example, Lembeck, 1983; Gulbenkian et al., 1986; and E. Scarfone D. Dememes, R. Jahn, P. De Camilli, and A. Sans, unpublished observations). Thus, both regulated pathways that operate in efferent nerve endings (De Camilli and Navone, 1987) might be operating also in sensory endings.

One cannot exclude, however, the possibility that microvesicles of sensory endings do not have the same secretory function 


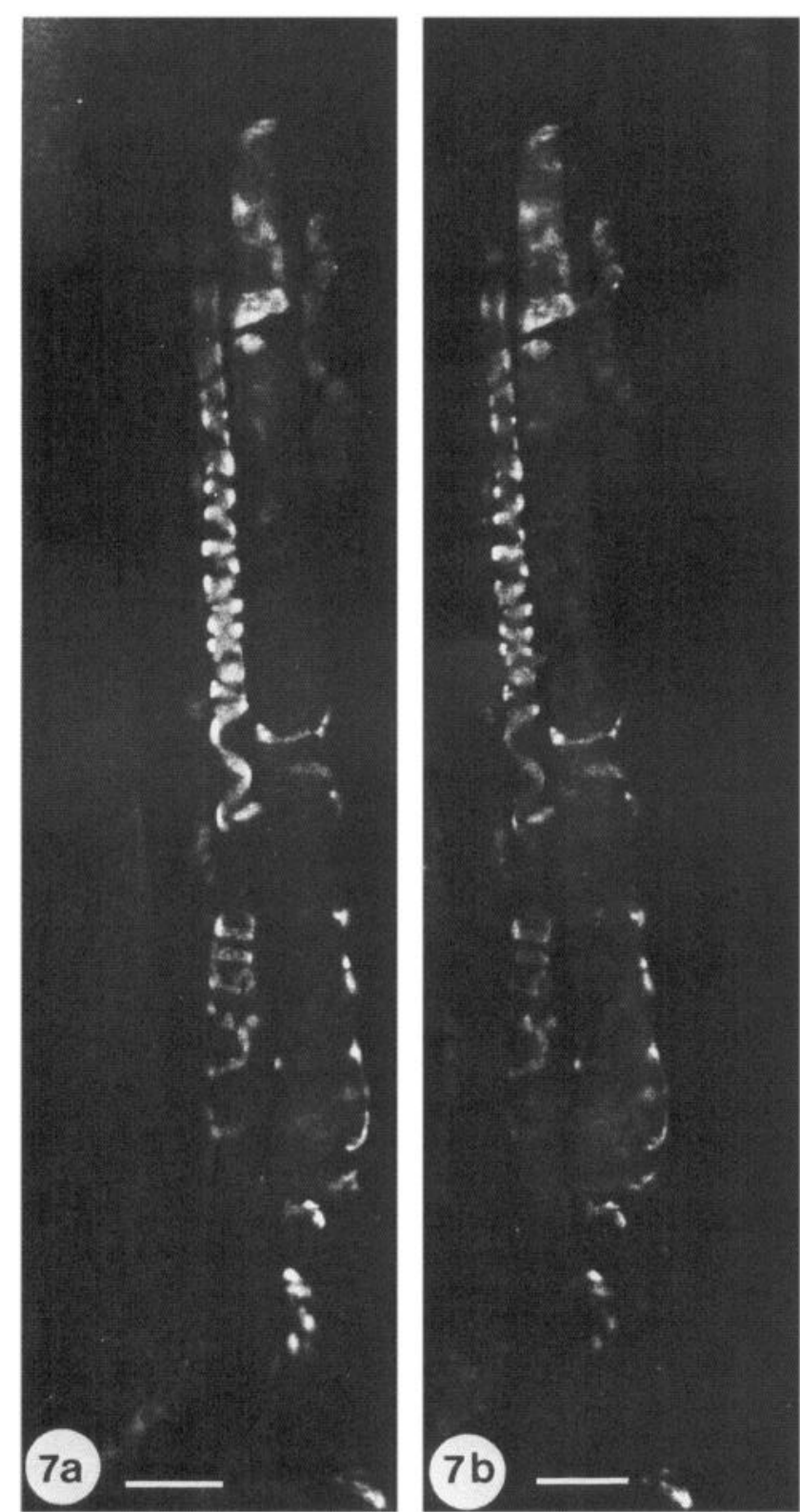

Figure 7. Double-labeling of the same muscle spindle for synapsin I by immunorhodamine $(a)$ and for synaptophysin by immunofluorescein (b). The 2 immunoreactivities have an identical distribution. Bars, 25 $\mu \mathrm{m}$.

of vesicles in efferent nerve endings, or that they do not have a secretory function. Recently a population of microvesicles biochemically related to small synaptic vesicles (they have synaptophysin but not synapsin I in their membranes) has been identified in non-neuronal neuroendocrine cells (Navone et al., 1986). The function of these endocrine microvesicles remains to be determined. Their discovery, however, has suggested that microvesicles of presynaptic endings belong to a class of organelles that can be involved in functions other than synaptic transmission.

In conclusion, our results suggest that microvesicles of sensory endings of the muscle share at least some important biochemical similarities with small synaptic vesicles of presynaptic efferent nerve terminals. Such results further emphasize the fact that, in spite of morphological and phsyiological differences, efferent and afferent nerve endings share some important common principle of organization. Our findings provide new clues for the understanding of the function of microvesicles in sensory endings and of the physiology of sensory endings in general.

\section{References}

Barker, R. (1974) The morphology of muscle receptors. In Handbook of Sensory Physiology, vol. 3, pt 2: Muscle Receptors, C. C. Hunt, ed., 190 pp., Springer-Verlag, Berlin.

Clark, H. F., and C. C. Sheppard (1963) A dialysis technique for preparing fluorescent antibody. Virology 20: 642-644.

De Camilli, P., and P. Greengard (1986) Synapsin I: A synaptic-vesicle associated neuronal phosphoprotein. Biochem. Pharmacol. 35: 4349.

De Camilli, P., and F. Navone (1987) Regulated secretory pathways of neurons and their relation to the regulated secretory pathways of endocrine cells. Ann. NY Acad. Sci. 493: 461-479.

De Camilli, P., R. Cameron, and P. Greengard (1983a) Synapsin I (protein I), a nerve terminal-specific phosphoprotein. I. Its general distribution in synapses of the central and peripheral nervous system demonstrated by immunofluorescence in frozen and plastic sections. J. Cell Biol. 96: 1331-1354.

De Camilli, P., S. M. Harris, Jr., W. B. Huttner, and P. Greengard (1983b) Synapsin I (protein I), a nerve terminal-specific phosphoprotein. II. Its specific association with synaptic vesicles demonstrated by immunocytochemistry in agarose-embedded synaptosomes. J. Cell Biol. 96: 1355-1373.

De Camilli, P., M. P. Canevini, R. Zanoni, M. Vitadello, C. Triban, and A. Gorio (1985) Synapsin I is present in both efferent and afferent nerve endings in skeletal muscle. Soc. Neurosci. Abstr. 11: 1131.

De Gennaro, L. J., S. Kanazir, W. C. Wallace, R. M. Lewis, and P. Greengard (1983) Neuron-specific phosphoproteins as models for neuronal gene expression. In Cold Spring Harbor Symp. Quant. Biol. 48: 337-345.

Favre, D., E. Scarfone, G. Di Gioia, P. De Camilli, and D. Dememes (1986) Presence of synapsin I in afferent and efferent nerve endings of vestibular sensory epithelia. Brain Res. 384: 379-382.

Golgi, C. (1903) Sui nervi dei tendini dell'uomo e di altri vertebrati e di un nuovo organo nervoso terminale musculo tendineo. In Opera Omnia, vol. 1, pp. 171-198, Hoepli, Milan.

Gulbenkian, S., A. Merighi, J. Wharton, I. M. Varndell, and J. M. Polak (1986) Ultrastructural evidence for the coexistence of calcitonin gene related peptide and substance $P$ in secretory vesicles of peripheral nerves in the guinea pig. J. Neurocytol. 15: 535-542.

Hurlbut, W. P., and B. Ceccarelli (1974) The use of black widow spider venom to study the release of neurotransmitter. Adv. Cytopharmacol. 3: $87-115$.

Huttner, W. B., L. J. De Gennaro, and P. Greengard (1981) Differential phosphorylation of multiple sites in purified protein I by cyclic AMPdependent and calcium-dependent protein kinases. J. Biol. Chem. 256: $1482-1488$.

Huttner, W. B., W. Schiebler, P. Greengard, and P. De Camilli (1983) Synapsin I (protein I), a nerve terminal-specific phosphoprotein. III. Its association with synaptic vesicles studied in a highly purified synaptic vesicle preparation. J. Cell Biol. 96: 1374-1388.

Jahn, R., W. Schiebler, C. Ouimet, and P. Greengard (1985) A 38,000dalton membrane protein (p38) present in synaptic vesicles. Proc. Natl. Acad. Sci. USA 82: 4137-4141.

Kennedy, M. B., and P. Greengard (1981) Two calcium/calmodulindependent protein kinases, which are highly concentrated in brain phosphorylate protein I at distinct sites. Proc. Natl. Acad. Sci. USA 77: 1293-1297.

Landon, D. N. (1972) The fine structure of the equatorial regions of developing muscle spindles in the rat. J. Neurocytol. 1: 189-210.

Lee, C. Y., S. L. Chang, S. T. Kau, and S. H. Luh (1972) Chromatographic separation of Bungarus multicinctus and characterization of its components. J. Chromatogr. 72: 71-82.

Lembeck, F. (1983) Sir Thomas Lewis's nocifensor system, histamine and substance $\mathrm{P}$-containing primary afferent nerves. Trends Neurosci. 6: 106-109.

Meldolesi, J., H. Scheer, L. Madeddu, and E. Wanke (1986) Mechanism of action of alpha-latrotoxin: The presynaptic stimulatory toxin 
of the black widow spider venom. Trends Pharmacol. Sci. 7: 151155.

Mori, H., Y. Komiya, and M. Kurokawa (1979) Slowly migrating axonal polypeptides. Inequalities in their rate and amount of transport between two branches of bifurcating axons. J. Cell Biol. 82: 174-184.

Navone, F., P. Greengard, and P. De Camilli (1984) Synapsin I in nerve terminals: Selective association with small synaptic vesicles. Science 226: 1209-1211.

Navone, F., R. Jahn, G. Di Gioia, H. Stukenbrok, P. Greengard, and P. De Camilli (1986) Protein p38: An integral membrane protein specific for small vesicles of neurons and neuroendocrine cells. J. Cell Biol. 103: 2511-2527.

Queiroz, L. S., and L. W. Duchen (1982) Effect of Latrodectus spider venoms on sensory and motor nerve terminals of muscle spindles. Proc. R. Soc. Lond. [Biol.] 216: 103-110.

Ramon y Cajal, S. (1911) Histologie du Système Nerveux de l'Homme et des Vertebres, vols. 1 and 2 (reprinted 1952 and 1955). Maloine, Paris.

Stone, G. C., and D. L. Wilson (1979) Qualitative analysis of protein rapidly transported in ventral horn motoneurons and bidirectionally from dorsal root ganglia. J. Neurobiol. 10: 1-12.
Thomason, B. M., and G. S. Cowart (1967) Evaluation of polyvinyl alcohols as semipermanent mountants for fluorescent antibody studies. J. Bacteriol. 93: 768-769.

Ueda, T., and P. Greengard (1977) Adenosine 3',5' monophosphateregulated phosphoprotein system of neuronal membranes. I. Solubilization, purification, and some properties of an endogenous phosphoprotein. J. Biol. Chem. 252: 5155-5163.

Valtorta, F., L. Madeddu, J. Meldolesi, and B. Ceccarelli (1984) Specific localization of the alpha-latrotoxin receptor in the nerve terminal plasma membrane. J. Cell Biol. 99: 124-132.

Vitadello, M., C. Triban, M. Fabris, A. Gorio, and S. Schiaffino (1986) Heterogeneity of rat neurofilament polypeptides revealed by a monoclonal antibody. J. Neurochem. 46: 665-670.

Watson, D. F., J. A. Donoso, J. P. Illanes, and F. E. Samson (1975) Comparison of transported proteins in the central and peripheral projections of unipolar neurons. Trans. Am. Soc. Neurochem. 61: 109.

Wiedenmann, B., and W. W. Franke (1985) Identification and localization of synaptophysin, an integral membrane glycoprotein of $M$ 38,000 characteristic of presynaptic vesicles. Cell 41: 1017-1028. 